\title{
L'ESCOLA D'ORGUE DEL MONESTIR DE MONTSERRAT
}

\author{
THE ORGAN SCHOOL OF MONTSERRAT MONASTERY
}

\section{LA ESCUELA DE ÓRGANO DEL MONASTERIO DE MONTSERRAT}

\author{
Daniel Codina i Giol \\ Arxiu de Música, Abadia de Montserrat \\ dcodina@abadiamontserrat.net \\ ORCID iD: https://orcid.org/0000-0002-8261-9135
}

\section{Resum}

Recorregut històric i bibliogràfi c de l'estudi de l'orgue al monestir de Montserrat, en funció de les necessitats pedagògiques de l'escola de música i de les funcions litúrgiques. S'inclou la llista de monjos organistes. Es parla també del material escrit per a l'estudi que ha quedat.

\section{Paraules clau}

Monestir de Montserrat, Escola d'orgue, Funcions litúrgiques, Monjos organistes, manuscrits musicals.

\begin{abstract}
Historical and bibliographic tour of the study of the organ in the monastery of Montserrat, according to the pedagogical needs of the music school and the liturgical services. The list of organist monks is included. There is also talk about written material for the study that has been preserved.
\end{abstract}

\section{ENTRADA}

L'aprenentatge de l'orgue a Montserrat, tot i les llacunes històriques i documentals, pot ser estudiat de manera prou seguida a partir del moment que coneixem les primeres obres escrites i no tant pel coneixement que puguem tenir dels deixebles de l'escolania, especialment dels que no van quedar-se al monestir com a monjos. La idea d'aquest treball va néixer en constatar la documentació, diguem-ne, pedagògica, que existeix a l'arxiu de música a partir de la primera restauració de l'escola musical el 1818 després del tall produït per la guerra del Francès: els dos músics que més van treballar per refer l'escola van haver de crear de nou tot el material pedagògic per als nois que començaven. Els dos mestres, el P. Jacint Boada i Casanoves $(* 1772 ; \uparrow 1859)$ i el P. Benet Brell i Clos

(C) 2018 CSIC. Este es un artículo de acceso abierto distribuido bajo los términos de una licencia de uso y distribución Creative Commons Attribution 4.0 International (CC BY 4.0)

Cómo citar este artículo/Citation: Codina i Giol, D. (2018). L'escola d'orgue del monestir de Montserrat. Anuario Musical, 73: 123-134. doi: http://dx.doi.org/10.3989/ redc.2018.73.08

\section{Key Words}

Monastery of Montserrat, School of organ, Liturgical services, Organist monks, Musical manuscripts.

\section{Resumen}

Recorrido histórico y bibliográfico del estudio del órgano en el monasterio de Montserrat, en función de las necesidades pedagógicas de la escuela de música y de las funciones litúrgicas. Se incluye la lista de monjes organistas. Se habla también del material escrito para el estudio que se ha conservado.

\section{Palabras clave}

Monasterio de Montserrat, Escuela de órgano, Funciones litúrgicas, Monjes organistas, manuscritos musicales.

$(* 1786 ; \dagger 1850)$, portaven el bagatge après a l'escola montserratina de la segona meitat del segle divuitè regentada pels dos grans músics: el P. Anselm Viola i Valentí (*1738; †1798), mestre dels escolans, i el gran organista el P. Narcís Casanoves i Bertran $(* 1747$; $\uparrow 1799$ ). Aquest material escrit permet fer-nos una idea prou precisa del mètode d'estudi, si podem dir-ho així, que se seguia durant el segle dinou, que no devia pas ser gaire diferent del dels temps anteriors. Baltasar Saldoni $(* 1807 ; \dagger 1889)$, en el llibret que va escriure sobre l'escolania de Montserrat ${ }^{1}$, ens parla primer del que s'aprenia a l'escolania des del punt de vista musical:

1 SALDONI (1856). Aquest mateix autor, en l'altra obra en quatre volums que va escriure, SALDONI (1868), parla de diferents

ANUARIO MUSICAL, N. ${ }^{\circ} 73$, enero-diciembre 2018, 123-134. ISSN: 0211-3538 doi:10.3989/anuariomusical.2018.73.08 
"Sabido este [el solfeig], aprendian por lo general el organo, y en seguida la composicion... Puede decirse que eran varios los métodos de enseñanza adoptados en el colegio para cada instrumento, porque cada uno de los maestros de la Escolanía, escribía por lo regular para cada discipulo, aunque tocaran muchos un mismo instrumento, diferentes lecciones y ejercicios, sin contar con los que ya existian antiguos de dentro y fuera del colegio; así es que habia tal variedad de estudios que eso mismo contribuía á que los discípulos se acostumbraran á todo género y estilo de música"2.

I després ens proporciona algunes llistes dels antics alumnes, com ho va ser ell mateix, monjos i no monjos, que van estudiar orgue amb els quaderns d'estudi que van escriure Boada i Brell.

Els inicis de l'escola d'orgue ens resten completament foscos. Només podem fer hipòtesis des del moment que l'església monàstica disposava d'aquest instrument, que devia ser prou aviat, per acompanyar els oficis litúrgics cantats i havent-hi els nois escolans. Gràcies als treballs d'investigació i de recerca del malaguanyat pare Francesc Xavier Altés i Aguiló ${ }^{3}$, tenim algunes referències de l'existència de l'orgue a l'església vella, la romànica, a partir de la meitat del segle $\mathrm{XV}^{4}$. Respecte a aquest orgue, tant els costums de Montserrat, com les Constitucions que s'imposaren des de Valladolid, al moment de la reforma monàstica el 1493, parlen de com l'Ofici diví i altres actes de culte comporten la presència de l'orgue, sobretot en l'alternança amb el cor de monjos. Donat que l'espai de la capella antiga no era gaire gran l'orgue devia ser més aviat petit ${ }^{5}$; també se sap de l'existència d'alguns orgues portàtils pensats per a les processons a l'exterior del temple, a més de servir per a l'aprenentatge i de sostenir el cant dels escolans ${ }^{6}$. L'altra referència, com veurem més endavant, és l'existència ja abans de la construcció del gran orgue de l'església nova del 1603-1606, d'algun monjo, antic escolà, que era organista (Gran Organista, diu el Catalogo $)^{7}$. És a dir, el P. Joan Graner, que morí a Poblet l'any 1600 i d'altres que van entrar al noviciat a finals del s. XVI també havien estudiat orgue en la seva estada a l'escolania. De fet, l'estudi de l'orgue o dels instruments de teclat, era força generalitzat ja que, segons els estatuts donats per Garsias de Cisneros al moment de la Reforma, "el Maestro que tienen los Escolanes es un Monje...que sepa de Composicion y Organo, y de otros Ynstrumentos". D'abans

monjos antics escolans que de manera genèrica diu que van destacar en l'orgue, però que en les fonts manuscrites de què parlaré més endavant no se'n diu res. Llista que és represa per CORTADA (1998): 99-108.

2 SALDONI (1856): 23-24. De fet, es constata que molts dels quaderns que han quedat estan dedicats a un deixeble concret, tot i que després servien per a d'altres deixebles.

3 ALTÉS (2011): 19-47.

4 ALTÉS (2011): 20

5 Vegeu referències més precises a ORANIAS (en curs).

6 ALTÉS (2011): 22.

7 Catalogo: 8.

8 NOVIALA: 9. Cisneros, però, diu que el mestre ha de ser un clergue dels que hi havia a Montserrat per a l'atenció dels pelegrins; els monjos no seran mestres fins al segle XVII: el tractat de Noviala, escrit al segle XVIII, s'ha adaptat a les noves circumstàncies. del segle XVII, però, no tenim constància dels mestres músics $\mathrm{i}$, per tant, dels organistes que hi havia: l'ensenyament musical anava a càrrec o bé d'algun clergue que formava part del grup montserratí dedicat a la pastoral, o bé d'algun mestre contractat; i no és fins a primers del segle XVII que l'ensenyament musical a l'escolania recau sobre un monjo antic escolà, nomenat per l'abat; tradició que perdurarà gairebé ininterrompudament fins als nostres dies. Com que sortosament disposem de dos catàlegs o llistes de monjos antics escolans ${ }^{9}$, en forma de notes biogràfiques, sovint ens diuen de les seves habilitats en l'orgue, ni que sigui de manera molt succinta o genèrica. Cal tenir present que l'estudi de l'orgue significava també, l'estudi concret que es feia en instruments de teclat (espinetes, clavicordis, etc.), els quals es trobaven segurament en l'edifici de l'escolania on s'estudiava.

Així, cal tenir present que el Ceremonial Monástico que regia a Montserrat era el mateix que estava establert per a tota la Congregació de Valladolid ${ }^{10}$. En el capítol sisè s'especifica la normativa destinada a l'orgue i a l'organista, és a dir: en els temps litúrgics i festes establertes segons el grau de festivitat, en els oficis litúrgics i les misses, en els versos que alternaven amb el cor i en d'altres moments en què es pot tocar. Finalment, que s'han de tocar coses adients, i que els orgues estiguin afinats! "En matèria litúrgica i musical, Montserrat ja havia adoptat una normativa diferenciada en relació amb la influència vallisoletana, fet que reconeix l'abat Cisneros mateix en diverses constitucions pròpies del monestir català"11.

\section{CARACTERÍSTIQUES PRINCIPALS DE LES OBRES D'ORGUE}

A l'escola organística de Montserrat, igual com passava arreu de la península ibèrica i a Catalunya, les obres per a orgue que ens han pervingut, amb nom d'autor o anònimes, compleixen una doble finalitat: el de l'ús litúrgic en les misses $i$ els oficis divins i el de l'ensenyament ${ }^{12}$. Si les obres ens han arribat escrites, bàsicament és perquè ho van ser com a material d'aprenentatge de l'instrument i de les formes musicals, perquè molt sovint, per als moments de la litúrgia, l'organista expert improvisava les obres $i$, per tant, no han quedat registrades per escrit $^{13}$.

9 Catalogo i NOVIALA. Tots dos van ser confeccionats originariamente per defensar l'Escolania dels intents de supressió per part de la Congregació de Valladolid (treball en fase inicial de recollida de dades). Vegeu: CODINA (1995). Cal afegir-hi encara el llibret imprès del Pare Jaume Martí i Marvà [MARTÍ (1650): 29]: “[¿]Para que me canso al presente, hallará V. P. Rma. en Monserrate solo de organistas siete sin otros muchos que pudieran pasar en cualquier Iglesia por bonisimos?". Vegeu encara les pàgs. 43-57.

10 Ceremonial (1635).

11 CORTADA (1998): 166

12 CORTADA (1998): 155ss, dedica el capítol cinquè a "L'orgue en la litúrgia".

13 Com a exemple podem esmentar el cas del pare Narcís Casanoves, en la biografia del qual ens és dit que improvisava tant bé les sonates que tocava que haurien pogut anar directament a l'imprenta. 
En la literatura escrita ens trobem amb formes molt establertes que es van reproduint al llarg dels segles, amb les variants corresponents a l'evolució de l'estil musical i de la llibertat dels compositors, tot i que la terminologia no sempre és precisa, - tant com voldríem en l'època moderna - , i és variable segons els llocs, regions o països i també segons les èpoques.

La forma musical més corrent i utilitzada des de mitjan segle divuit és la Sonata o Tocata ${ }^{14}$. Com a forma pròpriament organística hi ha la Sonata per clarins, brillant, un xic espectacular $^{15}$.

D'altres formes característiques ben usuals són d'una part el Pas, una forma fugada, o imitativa, amb desenvolupament al mig i passatge cap a modulacions diferents. Aquesta forma la trobem en els autors de la segona meitat del segle divuit $i$ principis del dinou. En l'obra teòrica, encara inèdita, d'Antoni Codolar $(* 1721 ; \nmid 1773)$, monjo de Montserrat ${ }^{16}$, defineix així el

"Paso, o Intento no es otra cosa, que un pedazo de Musica suelto, mas, o menos dilatado, agradable, e imitable por otra, u otras vozes, y que en su prosecución regularmente suele observarse este orden: haviendo entrado todas las vozes el Paso, por el signo que mejor pareciese, se mudan las vozes, trocando los signos: luego se saca el paso de tono".

I més endavant encara parla del Sobreintento ${ }^{17}$. Pablo Nassarre ${ }^{18}$ precisa: "Y esta especie de musica, se practica tocando en llenos".

D'una altra part tenim el Partit, de mà dreta o de mà esquerra. Aquesta forma musical neix a Castella amb la troballa, vers 1560-1570, de construir els orgues d'un sol teclat amb alguns registres partits ${ }^{19}$, fet que possibilita tocar, en un sol teclat, registres i timbres diferents al mateix temps. El mateix teòric Nassarre $^{20}$ l'explica de la manera següent:

"Antiguamente no se usaba el tenerlos partidos [els orgues], como se invento despues; disponiendolos de modo, que los registros no fuesen mas que lo que la mitad del teclado, dividiendo en dos lo que antes era solo uno; dispuestos assi, para que la una mano pudiese tocar con el lleno del Organo, y la otra con el flautado: y a dicha invencion se siguio el inventar los Organistas las obras partidas, tanto de una mano como de otra; disponiendo, que una voz que avia de tocar en el lleno, fuese toda glosada, para la mano derecha era Tiple, y para la izquierda

14 Excel-lent estudi en el llibre CORTADA (1998): cap. sisè: "La Sonata i el clavicèmbal", 183 ss.

15 Un resum, a partir dels teòrics musicals espanyols, es troba a la Introducció de MEM (1992): XIV-XVI. Vegeu encara CODINA (1993). 181-182.

16 Examen musical, ms. nº. 990 de la Biblioteca de Montserrat,

17 Ibid., 184.

18 NASSARRE (1723): II, 481.

19 Vegeu: JAMBOU (1988): 139ss.; CODINA (1993); y MEM (1992): XVI.

20 NASSARRE (1723): II, 472-473. MEM (1992): XVI. era Baxo; y la otra mano llevava las tres vozes, sirviendo como de acompañamiento a la que llevava la glosa...”.

Podem precisar encara que la forma de Partit està construïda de manera imitativa, i comença per les veus que fan d'acompanyament. Aquesta forma musical ja la trobem utilitzada pel pare Miquel López el 1711 i continuada sobretot per Anselm Viola i Narcís Casanoves. En aquestes obres, la mà, esquerra o dreta (baix o tiple), era la que portava la veu cantant i florida després d'entrar de forma fugada amb el tema exposat per l'altra mà. Una forma que demanava una gran tècnica: per això es proposava com a forma important d'ensenyament de l'instrument ${ }^{21}$.

L'altra gran gènere utilitzat són els versos, que s'intercalaven, o bé en els salms de l'ofici coral, o bé, posteriorment, en els cants de l'ordinari de la missa. Això vol dir que es formaven grups o sèries de versos d'un mateix mode o tonalitat $i$, sobretot en les èpoques més antigues, estava establert, sense que fos una regla escrita, que incloïen diferents gèneres musicals: Plens, Partits, Passos, etc. Sovint eren curts: quatre o més compassos, que cantaven tota una frase musical. Va ser una gènere molt utilitzat per a l'ensenyament i la pràctica de l'orgue, al mateix temps que iniciava el deixeble a saber improvisar. En els arxius musicals se n'han conservat una quantitat ingent, i sovint ja es componien en sèries segons els vuit modes eclesiàstics utilitzats en la salmòdia.

\section{LLISTA DELS MONJOS ORGANISTES}

Jeroni ROTÉS, de Solsona. Entrà al noviciat l'any 1515 i morí el 1571. D’ell es diu: "Insigne en todo género de Musica"22; devia tocar bé l'orgue.

Joan GRANER, de Palma d'Ebre. Noviciat 1574; mort a Poblet l'any 1600. S'anota: "Gran Organista"23.

Jeroni CASTELL, de Sant Feliu de Guíxols. Noviciat el 1586; mort el 1621. Es diu: "Fue diestrissimo en musica y gran organista" 24 . A partir d'aquest ja feien servir l'orgue gran de l'església nova, però, d'escolà, devia haver après a tocar en l'orgue de l'església vella.

Miquel de VILLALBA, de Saragossa. Noviciat el 1595; no s'indica la data de la mort perquè devia morir fora de Montserrat. Es diu que va ser mestre dels escolans ${ }^{25}$.

21 És incomprensible que el gran Diccionario de la Música Española e Hispanoamericana de SGAE (2000), a la veu Partido digui només això: "Forma musical propia de la música para órgano. Véase Tiento".

22 Catalogo: n. 12, 4. NOVIALA: 51, li asigna el n. 13 en la seva llista i en la p. 89 el cita amb els càrrecs que va exercir i li diu: "Muy diestro en Musica".

23 Catalogo: n. 28, 8. NOVIALA: 52, li dóna el cognom de GAVER i li asigna el n. 23 de la llista i diu que va prendre l'hàbit de monjo l'any 1575 i a la p. 90 diu d'ell: "Excelente Organista y musico; fue muchos años Cantor Mayor".

24 Catalogo: n. 32, 8. NOVIALA: 53-54 i 90, li assigna el n. 32.

25 Catalogo: n. 34, 9. NOVIALA: 55, li asigna el n. 42. Desconeixem l'abast de la frase "mestre dels escolans", en tot cas no hi ha cap referència a la música. 
Pere de VILAGRASSA, de Binacet. Noviciat 1596; mort el 1613. Es diu d'ell: "Fue grande Musico", per tant devia tocar bé l'orgue ${ }^{26}$, tot i la seva curta vida monàstica.

Bernat BARECHA, de Binacet. Noviciat el 1596; no s'indica la data de la seva mort. Mestre dels escolans molts anys ${ }^{27}$.

Joan MARC, d'Arbeca. Noviciat el 1596; mort el 1658. Fou mestre de Capella i "Organista de los de primera magnitud" 28 . D'estudiant a Madrid va ser organista del monestir de San Martin i de Las Descalzas Reales, en substitució de Tomás Luis de Victoria, mort el 1611. A l'escolania va formar molts bons deixebles, entre ells Joan Cererols. Va compondre molta música vocal, però ens n'ha pervingut molt poca.

Jaume ISALGUER, de Sant Joan de les Abadesses. Noviciat el 1598; mort el 1645: "Organista, Sacristan segundo..." ${ }^{29}$.

Francesc ROSSELL, de santa Coloma de Centelles. Noviciat el 1607; mort el 1634. S'escriu d'ell: "Fue muy diestro en tocar Organo y Baxon"30.

Antoni ROMANO, de Palerm (Sicília). Noviciat el 1610: mort el 1660. "Era diestro en Musica" 31.

Jaume MARTÍ I MARVÀ, de Vallmanya. Noviciat el 1610 , mort el 1678. "Fué insigne sugeto asi en letras com en Musica" 32 .

Miquel BARECHA, de Binacet. Noviciat el 1617, mort el 1628. "Diestro en Musica"33

Pere ROCA, de Cornudella. Noviciat 1627, mort 1651. "Fue grande Organista y Compositor, discipulo del $\mathrm{P}^{\mathrm{e}} . \mathrm{M}^{\mathrm{o}}$. Marques"34.

Jaume VIDAL, de Sant Feliu de Llobregat. Noviciat 1630, mort 1689. "Fue uno de los buenos Musicos que tubo en su tiempo esta $\mathrm{S}^{\text {ta }}$ Casa" 35 .

\section{Catalogo: n. 29, 8}

27 Catalogo: n. 36, 10. NOVIALA li assigna el n. 43 de la seva llista i a les pp. 91-92 explicita més detalladament la seva feina entre els escolans, dels quals va ser-ne el primer monjo mestre de música nomenat per a aquest càrrec. "Diestro en música", diu NOVIALA: 91.

28 Catalogo: n. 37, 10. NOVIALA: 93, diu: "El P[adr]e Fr. Juan Marquez, fue en su tiempo de los mejores Organistas de España. Maestro de Capilla, Organista en esta Casa y en S. Martin de Madrid [afegit en el marge] y en el Mon[asteri]o de las Descalzas de Madrid". MARTÍ (1650): 35, escriu: "No hallo segundo en su facultad de órgano y composición, ha sacado muchos libros de misas, Completas, Magnificats, y ahora [Marvà va escriure el llibret l'any 1641, però editat el 1650: vegeu: CODINA (2013): 37] está acabando uno del numero de quatro que dexara atrás à personas de ciencias mayores".

29 NOVIALA: 93.

30 Catalogo: $\mathrm{n} 44,12$; NOVIALA: 93-94.

31 Catalogo: n. 49, 14. NOVIALA: 95, ens informa de la seves aptituds musicals.

32 Catalogo: n. 58, 17. Va publicar el llibret en defensa de l'Escolania: MARTÍ (1650)

33 NOVIALA: 103. A la llista, p. 56, li assigna el n.38.

34 Catalogo: n. 67, 19.

35 Catalogo: n. 69, 19. CODINA \& SANS (1989), edició de dues conferències sobre el personatge fetes a Sant Faliu de Llobregat en motiu dels 300 anys de la seva mort.
Josep MAGAROLA, de Barcelona. Noviciat 1628, mort el 1676. "Fue doctissimo assi en Musica Como en letras"36.

Joan ROMANYÀ, de Piera. Noviciat el 1632, mort el 1687. "Fue excelente Musico, y gran Compositor de Gallardas y tocatas para chirimias, grande Organista" 37 .

Pere JORBA, de Terrassa. Noviciat el 1635, mort el 1647. "Fue grande organista en que mostro ser discipulo del $\mathrm{P}^{\mathrm{e}} \mathbf{M}^{\mathrm{o}}$. Marquez"38.

Gregori CODINA, de Martorell. Noviciat l'any 1635, mort l'any 1679. "Grande compositor de musica", per tant devia tocar bé l'orgue ${ }^{39}$.

Joan CEREROLS de Martorell. Noviciat 1636, mort el 1680.

"Tubo don y gracia para en Señar y assi tubo tantos discipulos que apenas avia Iglesia en este principado que sus Maestros de Capilla y Organistas no fuesen discipulos suyos, sin otros muchos que tubo en otras provincias de España en que manifestaron las excelentes prendas de $\mathrm{Su}$ Maestro, Como su $\mathrm{P}^{\mathrm{d}}$ mostro tambien las del $\mathrm{P}^{\mathrm{e}}$ Maestro Marquez de quien era discipulo, fue juntamente gran tocador de violin (corregit per: violon), Arpa, organo, Archilaud, y todo instrumento de cuerda, trompa marina y violon"40.

Joan GELON, de Conques (Catalunya). Noviciat el 1637, mort el 1671. "Fue Maestro de los Niños Escolanes"41.

Josep BASSÓ, de Sant Feliu de Guíxols. Noviciat el 1638, mort el 1652. "Fue lindo organista, buen Compositor" 42 .

Joan SIMÓ, d'Arbeca. Noviciat l'any 1643, mort a Cazères (Llenguadoc, França) el dia 10 de maig de l'any 1678. "En

36 Catalogo: n. 71, 23.

37 Catalogo: n. 72, 23. Una nota al marge diu. "Fue discipulo del Mํo Marques". ANGLÉS (1962): 8, escriu: "La escuela organística española durante el siglo XVII queda representada, entre otros maestros, por Juan Romanyà, quien vistió la cogulla de benedictino en Montserrat, el año 1632; fue compositor de fama y organista muy admirado por sus contemporáneos. Célebre por sus tocatas para espineta y sus gallardas para chirimías, que desgraciadamente no han llegado hasta nosotros. Más afortunados, en cambio, en el repertorio conservado de otro benedictino de Montserrat, Don Juan B ${ }^{\text {a }}$ Rocabert... organista famoso en la iglesia de San Martin de Madrid", del qual tampoc s'han conservat les obres, i cita QUEROL (1961): cols. 536-541. NOVIALA: 97: "M[aest]ro de Capilla, Organista", i en la p. 60, $\mathrm{n}^{\circ} 73$, diu que va morir l'any1642, quan nonmés tindria 10 anys d'estada al monestir.

38 Catalogo: n. 74, 24; NOVIALA: 97, El P[adr]e Fr. Pedro Jorba, Organista".

39 Catalogo: n. 119, 39. NOVIALA: 61, li asigna el n. 77; i a la p. 97 el cita com a Pere Codina "Compositor de Musica".

40 Catalogo: n. 75, 24. NOVIALA: 97-98: "La Mayor parte de su vida fue M[aest]ro de los Niños Escolanes y de Capilla... Supo tañer el Violon, Arpa, Organo, Archilaud, y otros instrumentos". Vegeu: Actes (1985). Vegeu també: CODINA (2013).

41 Catalogo: n. 78, 25. Com a Mestre dels escolans havia de ser un músic complet. I deixeble del P. Marc o Marquès.

42 Catalogo: n. 81, 25. 
la facultad de organo fue muy Singular y no tubo ygual en su tiempo, y dexo muchas obras escritas de Musica"43.

Josep SELLARÈS, de Barcelona. Noviciat l'any 1644, mort 1686. "Fue sugeto muy Cabal assi en la musica como en letras" 44

Francesc ROSSELL, de Barcelona. Noviciat l'any 1646, mort 1676. "Fue gran Compositor en la musica, Como lo acreditan sus muchas y buenas obras, y fue Insigne Organista" 45 .

Leandre SERVANTÍ, de Barcelona. Noviciat l'any 1650, mort l'any 1690. "Le Inviaron à S. Martin de Santiago, donde estuvo algun tiempo por organista" 46 .

Benet SOLER, de Granollers. Noviciat l'any 1656, mort l'any 1682. "Lindo Compositor, y excelente Arpista, fué maestro de Escolanes"47.

Joan PONGEM, de Mataró. Noviciat l'any1659, mort el 1695. A l'Escolania “aprendio musica y salio muy Cabal organista"48.

Miquel PUJOL, de Llançà. Noviciat l'any 1659, mort el 1708. "Aprendio la musica con facilidad... que en breve tiempo salio tan aprovechado que fue uno de los mejores musicos que tubo esta casa en su tiempo, en particular fue gran organista"49.

Emilià TRULLÀS, de Vic. Noviciat l'any 1653, mort 1680 "Fue maestro de Escolanes muchos años"

Josep SALES, de Sanahuja. Noviciat el 1666, mort el 1678. "Fué muy buen organista"

Joan GARCIA, de Cellas (Aragó) [= Cella, Terol]. Noviciat l'any1669, mort, l'any 1707. D'escolà va ser “de tal Comprehension que en breves dias sin mucho Trabajo, se hallo Musico y Organista consumado"... "entre otras habilidades fue grande Organista" 52 .

Isidor ROY, de Lécera (Aragó). Noviciat, l'any 1670, mort, el 1720. "M[aest]ro de Escolanes, muy diestro en el Arpa"53.

Joan GENÍS o SANGENÍS, de Santa Coloma de Queralt. Noviciat l'any 1671, mort l'any 1675, amb el cognom de Joan Sangenís en el llibre d'Òbits. "Fue muy buen organista" ${ }_{54}$.

43 Catalogo: n. 86, 26; NOVIALA: 88, "El P[adr]e Fr. Juan Simó no tuvo igual en su tiempo en Organo". Archives municipales de Cazères, llibre de defuncions de la parròquia (notícies escrites per Robert Foch l'any 2008). Actualment només es coneix un villancet de Nadal que es troba a l'arxiu parroquial de Canet de Mar.

44 Catalogo: n. 87, 26.

45 Catalogo: n. 89, 26

46 Catalogo: n. 99, 29.

47 Catalogo: n. 100, 29. NOVIALA: 101: M[aest]ro de Escolanes. Fue grande Músico, el qual dexo algunas obras desta facultad". Va succeir el P. Cererols en el mestratge de l'escolania, però només dos anys perquè va morir.

48 Catalogo: n. 103, 31-33.

49 Catalogo: n. 104, 33-35.

50 Catalogo: n. 105, 35.

51 Catalogo: n. 84, 26.

52 Catalogo: n. 128, 40. NOVIALA: 102 "El P[adr]e Fr. Juan Garcia, Organista, Compositor de Musica, Mro. de los Escolanes. A instancia suya recompuso el Organo grande, o casi se hizo todo nuevo, poniendo registros a lo Moderno".

53 NOVIALA: 104.

54 Catalogo: n. 113, 38.
Joan Baptista ROCABERT, de Barcelona. Noviciat l'any 1674, mort a Sant Martin de Madrid l'any 1701.

"Sobre el grado de perfeccion que Consiguio en las facultades de organo y musica de que dan testimonio en las mas Capillas de España, las muchas obras que dejó à la posteridad Compuestas, no le faltaron las de Arpa, Violon, y demas Instrumentos de Cuerda, y en lo que toca a las referidas prendas de organo y musica, en su tiempo nayde llego a adelantarle" 55 .

Pau PRATS, de Caldes de Montbui. Noviciat, el 1680, mort al monestir de Banyoles, l'any 1705. "Tubo buenos principios de musica y organo" 56 .

Joan PALMERS, de Sabadell. Noviciat l'any 1684, mort l'any 1706. Va acabar l'escolania "adelantado en el organo" 57.

Miquel LÓPEZ, de Villaroya, d'Aragó. Noviciat l'any 1684, mort el 1723. "Fue Maestro de Escolanes y de Capilla dos vezes, Organista en esta Casa, en Madrid, y Valladolid" 58 .

Vicenç PRESIACH, de Morella. Noviciat, l'any1689, mort el 1726. "Organista, M[aest]ro de Capilla y de los Niños Escolanes, el qual dexo muchas obras de Musica assi en Latin como en Romanze" 59 .

Benet ESTEVE, de Capellades. Noviciat l'any1721, mort l'any 1772. Va ser mestre de l'escolania, amb bona formació musical $^{60}$.

Jeroni CASANOVES, de Granollers. Noviciat l'any 1688 , mort el 1721. "Diestro en tañer el Baxon. Organista"61.

Benet VALLS, de Sabadell. Noviciat l'any 1730, mort l'any 1782. Organista i segurament mestre d'orgue del P. Narcís Casanoves $^{62}$.

Felip ANDREU, de Granollers. Noviciat l'any 1744, mort l'any 1770. "Fue buen Compositor"63.

55 Catalogo: n. 129, 42-43. NOVIALA: 101-102: "M[aest]ro de Capilla y de Escolanes, compositor de Música, el q[ua]l dexo muchas Obras de Esta Facultadnassi p $p^{a}$ Cantar, como pa Organo. Supo tañer Arpa, Violon, y otros Instrumentos...Fue Organista de Sn. Martin de Madrid en donde murio". De moment no s'ha trobat cap obra escrita de música. Vegeu nota 18.

56 Catalogo: n. 131, 43.

57 Catalogo: n. 132, 43-44.

58 NOVIALA: 104. Estudi ben documentat de SEGARRA (1970): 13-14. És el primer de qui es conserven obres d'orgue, algunes amb caire netament pedagògic.

59 NOVIALA: 106.

60 Catalogo: n. 150, 46: Llibre d'Òbits, fol. 33; NOVIALA: 191-197 descriu tot el que va fer per l'Escolania: orgue nou per al cant de la capella al presbiteri (orgue d'Antoni Buscà i Llores), instruments per a assejar i per tocar a la capella, llits nous i sufivcients per als escolans i inici del nou edifici de l'escolania.

61 NOVIALA: 105. A la llista li assigna el n. 140, pp. 70-71.

62 Catalogo: n. 152, 46; Llibre d'Òbits, fol. 39; NOVIALA: 74 en parla molt breument $\mathrm{i}$ no diu que fos organista; la nota està escrita encara en vida seva i no era encara organista famós.

63 Catalogo: n.156, 47; Llibre d'Òbits, fol. 21r. 
Benet JULIÀ, de Torroella de Montgrí. Noviciat l'any 1745, mort 1787. "Fué Organista y tambien M[aes]tro de Escolanes". Ha deixat escrites algunes obres d'orgue ${ }^{64}$.

Josep MARTÍ I ROSSELLÓ, de Tortosa. Noviciat, el 1749, mort l'any1763. Quant a la formació musical no pertany a l'escola montserratina i no sabem on es va formar; en canvi va ser mestre d'aquesta escola i es conserven algunes sonates d'ell per a l'estudi dels escolans. Abans d'entrar a Montserrat exercia d'organista i mestre de capella a l'església de La Soledad de Madrid $^{65}$.

Isidor CAPDEVILA, de Sabadell. Noviciat l'any1750, mort l'any 1802. "en la Escolania...se adelantó en el estudio del Violin y (afegit) Organo"66.

Anselm VIOLA I VALENTÍ, de Torroella de Montgrí. Noviciat l'any 1756, mort l'any 1798 . Gran mestre de l'escolania, ha deixat bones obres per orgue ${ }^{67}$.

Miquel CARDELLACH, de Tarrassa. Noviciat l'any1758, mort l'any 1809. "Tocaba bien el Organo"68.

Bernat SASTRE, de Piera. Noviciat l'any 1759, mort l'any 1810. "Sabia tocar el Organo y la Flauta"69.

Agustí TRILLA, de Valls. Noviciat l'any 1760, mort l'any 1810. "La mayor parte del tiempo pasó en Bages en donde era Organista"

Narcís CASANOVES I BERTRAN, de Sabadell. Noviciat l'any 1763, mort el 1799. "lo que mas le distinguio fué su manejo y destreza admirable en tocar el Organo" 71 . I continua el mateix biògraf "Tocaba de repente (vol dir improvisadament) unas sonatas tan bien acabadas, que a juicio de los inteligentes merecian, sin añadir ni quitar nada, la imprenta". I encara d'ell, en el mateix text biogràfic tenim l'elogi que en féu un viatger, no sabem si del país o de fora: en entrar a l'església sentí tocar el P. Casanoves,

"se quedo fixo y como arrebatado mirando siempre el Organo, y despues dixo: soy inteligente en la música, y acabo de seguir casi toda Europa, y jamas he oido tocar tan bien el Organo como hoy".

I encara tenim el curt testimoni de Ferran Sor que diu d'ell:

64 Catalogo: n. 159, 49. MEM (1989).

65 RÀFOLS (1801): 107. També Llibre de vesticions (16661832, fols.66v-67r) i Llibre d'Òbits 1653-1887, Fol.20v), ambdós de l'arxiu de Montserrat.

66 Catalogo: n. 160, 49.

67 Catalogo: n. 161, 50. CORTADA (1998).

68 Catalogo: n. 158, 47-48. SALDONI (1856): 55: "Excelente organista".

69 Catalogo: n. 162,51

70 Catalogo: n. $163,52$.

71 Catalogo: n.164, 52-53. Totes les seves obres per orgue o teclat esstan editades a la col-lecció Mestres de l'Escolania de Montserrat (MEM): Instrumental I (Montserrat 1934) i MME (1992) i encara CODINA \& MOSCA (1997).
"No puc deixar de dir amb quin gust tan deliciós Casanoves acompanyava a l'orgue. El baix que utilitzava no era pas el cant pla mateix, sinó un excel-lent baix posant sota la melodia" 72 .

En els diferents quaderns d'estudi per a els escolans, sovint hi ha obres d'ell per a l'estudi de l'instrument.

Felip RODRÍGUEZ, de Madrid. Noviciat l'any 1778, mort l'any 1814. "Fué buen Organista...Escribió un libro de sonatas para Organo"73.

Maur AMETLLER, de Palafrugell. Noviciat l'any 1786, mort el 1833. Tenia una bona formació musical i va ser inventor d'un instrument de tecla anomenat "Velacordi""

Josep VINYALS, de Tarrassa. Noviciat l'any 1791, mort el 1825. "Fué Maestro de Escolanes, y Organista de esta Casa y ultimamente de Bages"

Martí SUNYER, de Roses. Noviciat l'any 1793, mort el 1842. "Fue Maestro de Escolanes algun tiempo"76.

Benet BRELL I CLOS, de Barcelona. Noviciat l'any 1803 , mort el 1850 .

"Estuvo en la Escolania siete años, haciendo en poco tiempo rapidos progresos en el Organo, fue ya desde escolan un organista aventajado, y tocaba con frecuencia y a veces temporadas el Organo grande en los oficios de la Comunidad, y al tomar el S[an]to habito... era ya un excelente Organista"77.

Jacint BOADA I CASANOVES, de Tarrassa. Noviciat l'any 1790 , mort l'any 1859 . "Compuso toda la música que hacia falta para el culto y la Escolania”, en especial versos i sonates per a l'estudi d'aquest instrument dels escolans ${ }^{78}$.

Rafael PALAU, de Granollers. Va professar de monjo l'any 1827 , el 18 de febrer de 1835 va ser nomenat Mestre de l'escolania, mort el 1890 a La Garriga. Durant l'exclaustració va ser organista i mestre de Capella de Montpeller i Granollers ${ }^{79}$.

Aquesta llista prou llarga, que abasta fet i fet tres segles, no ens revela res massa concret respecte a l'ensenyament de

72 De SOR (1835): 157, col. 2, reproduit a JEFFERY (1977) a partir de p. 167. La traducció del francès és meva.

73 Catalogo: $n$. 166, 53.Algunes sonates han estat editades pel P. David Pujol a MEM [MEM (1936)].

74 Catalogo: n. 167, 53-54. CODINA (2000): 39-47.

75 Catalogo: n. 169, 55. Té editada una sonata per a teclat a MEM (1936): 237-249.

76 Catalogo: n. 170, 55. Tocava bé el violí, però també devia ser expert en l'orgue.

77 Catalogo: $n .172,56$. Remarcable l'elogi com a organista que en fa SALDONI (1856): 51-52. Ha deixat força sonates per a estudi, algunes de les quals han estat editades: Benet Brell (2007) i Jacint Boada (1989).

78 Catalogo: n. 173, 56-57. Vegeu nota anterior.

79 Catalogo: va portar les seves obres a l'arxiu de música de Montserrat. SALDONI (1856): 54-68 dóna dues llistes d'antics alumnes de l'escolania, generalment no monjos de Montserrat, que van excel·lir en la funció d'organistes: abarca des del 1750 al 1836. 
l'orgue, però sí que ens mostra que aquest era un ensenyament musical prou estès, bàsic, podríem dir, dintre de l'escola ${ }^{80}$. És clar que caldria afegir-hi altres noms d'antics deixebles que no van ser monjos i, possiblement, alguns pogueren exercir d'organistes en catedrals o esglésies importants del país, de la mateixa manera que força antics alumnes van ser mestres de capella o instrumentistes, com es diu, per exemple, dels deixebles del P. Cererols, i dels que és molt difícil saber-ne els noms. Un deixeble de l'escolania certament important fou Antoni Soler i Ramos (*1729; †1783), que devia aprendre l'orgue amb el pare Benet Valls i va tenir de mestre d'escolans el pare Benet Esteve ${ }^{81}$. En sortir de l'escolania va exercir d'organista i mestre de capella a la catedral de Lleida ${ }^{82}$, fins que ben aviat va poder ser monjo jeroni a l'Escorial: dins la seva llarga producció de sonates per a clave té algunes obres específiques per a orgue ${ }^{83}$. Soler mateix escriu a Satisfacción a los reparos precisos hechos por don Antonio Roel del Rio a la Llave de la modulación, Madrid, 1765:

"Siendo yo de 13 á 14 años de edad, tengo muy presente que aprendí 24 obras de Organo del Señor Maestro Don Joseph Elias" $" 84$.

\section{OBRES PER A ORGUE DELS MÚSICS DE MONTSERRAT}

El primer del qual s'han conservat obres per a orgue escrites és el pare Miquel López $(* 1669 ; \nmid 1723)$, amb una producció clarament pedagògica, producció que ha estat editada dintre la col-lecció montserratina Mestres de l'escolania de Montserrat, per David Pujol i Gregori Estrada.

Taula d'obres per a orgue

\begin{tabular}{|l|l|l|l|l|}
\hline \multicolumn{1}{|c|}{ obra } & \multicolumn{1}{c|}{ lloc } & \multicolumn{1}{c|}{ any } & \multicolumn{1}{c|}{ pàg. ms. } & $\mathbf{n}^{\mathbf{0}}$ ordre \\
\hline Verso para la entrada de la Salve & S. Juan de la Peña & 1719 & 128 & 103 \\
\hline Verso para la entrada de la Salve & S. Juan de la Peña & 1719 & 147 & 104 \\
\hline *Pange lingua & Montserrat & 1702 & $148-150$ & 105 \\
\hline *Pange lingua & Montserrat & 1702 & $150-153$ & 106 \\
\hline *Pange lingua & S. Victorián & 1719 & $154-157$ & 107 \\
\hline *Pange lingua & S. Victorián & & $157-160$ & 108 \\
\hline *Sacris solemniis, a dos Baxos & Madrid & 1696 & $161-162$ & 109 \\
\hline *Sacris solemniis & Madrid & 1696 & $200-201$ & 110 \\
\hline *Pange lingua & Valladolid & 1707 & $206-207$ & 111 \\
\hline *Pange lingua. Eco, contraeco, suspension & S. Victorián & 1719 & $208-209$ & 112 \\
\hline Lleno para Niños que no alcanzan la octava & Valladolid & 1710 & $211-219$ i 221-223 & 113 \\
\hline Para que los Muchachos aprendan a tañer con eco y contraeco & Valladolid & 1705 & $262-270$ & 114 \\
\hline Lleno para Organo & S. Juan de la Peña & 1719 & $564-565$ & 115 \\
\hline Lleno & S. Juan de la Peña & 1719 & $565-567$ & 116 \\
\hline Versos para la Psalmodia & Montserrat & 1701 & $568-574$ & 117 \\
\hline Versos para la Psalmodia & S. Victorián & 1719 & $574-579$ & 118 \\
\hline Versos para diferenciar, en estos ocho términos, o Modos & & & $579-588$ & 119 \\
\hline Partido para mano derecha & Valladolid & 1711 & $588-589$ & 120 \\
\hline Versos por Primero, punto baxo & Valladolid & 1710 & $589-590$ & 121 \\
\hline
\end{tabular}

80 L'ensenyament de l'orgue estava destinat fonamentalment per a les funcions litúrgiques i religioses: d'ací la gran quantitat de versos alternatius per a la missa o la salmòdia.

81 RUBIO (1980): 15.

82 A Montserrat hi havia un cert costum que procurava que els deixebles més aprofitats que no es feien monjos, a la sortida tinguessin ja un lloc on exercir o a participar a unes oposicions per a organistes o mestres de capella.

83 RUBIO (1980): nn. 465-471, 135-137. També té: "Seis conciertos de dos órganos", $\mathrm{n}^{\circ}$. 463. Vegeu: KENYON (1985): 41-45.
84 RUBIO (1980): 18; ANGLÉS (1962): 6; CAPDEPÓN (2000): 32-33. Vegeu encara: LLORENS (1985): 23-28. Josep Elias va néixer a Moià l'any 1690; va ser organista de sant Pere de les Puel·les de Barcelona (1712-1715), de la parròquia de Sant Just i Pastor, de Barcelona (1715-1725) i del monestir de las Descalzas reales de Madrid (1725); morí a Madrid entre el 1758 i el 1759. 
Segons la taula precedent extreta de la llista d'obres feta pel pare Ireneu Segarra ${ }^{85}$, López ha deixat escrites 19 obres $^{86}$ totes elles pensades per a l'estudi de l'instrument i, algunes, pensades especialment per als escolans o per a nens que estudiessin l'orgue des de petits. La importància de López en la història de la música hispana la posa en relleu A. Martín Moreno ${ }^{87}$, quan escriu:

"El estudio de la música de fray Miguel López es fundamental para conocer la situación de la música española antes de la invasión del italianismo. Con este maestro comienza una evolución hacia el estilo polifónico instrumental en Montserrat, que va a ser continuado por sus sucesores".

El segon mestre és el pare Josep Martí (*1719; †1763), fill de Tortosa. No va estudiar a l'escolania: quan es va fer monjo de Montserrat tenia uns trenta anys i exercia d'organista a col-legi de la Soledad de Madrid. En arribar a Montserrat l'any 1749, per l'experiència musical que tenia, de seguida després del noviciat el van nomenar mestre dels escolans, on va fer un gran treball durant nou anys i mig i va compondre diferents obres vocals: Lamentacions, responsoris, un Stabat Mater, etc. i algunes sonates per a teclat. Martí és el qui aporta un nou estil musical que trenca amb el barroc.

Obres per a teclat

Sonata en Fa M, AMM 61, 7-8; 63, 33; 2158, 46-47.

Sonata en Re m, AMM 575, 11-12; 63, 21-22.

Sonata en Re M, AMM 63, 22-23; 2158, 45-46.

Sonata en Re m, AMM 63, 34; 2158, 47.

Fandango con Variaciones Para el Forte piano De José Martíy, ms. Roda 355 del Conservatori de Madrid ${ }^{88}$. Hi ha tres Sonates més al manuscrit AMM 2158, 48-50, són les sonates 25, 26 i 27 que se li poden atribuir. A més, té una Alemanda per a instruments a 3 veus per acompanyar el viàtic dels monjos, AMM 53, 23.

El tercer mestre de qui es conserven obres per a orgue és el pare Benet Julià $(* 1727 ; \uparrow 1787)$. A l'escolania va ser condeixeble amb Antoni Soler i Ramos (*1729; †1783), essent mestre el pare Benet Esteve. Julià es troba a cavall del barroc i el classicisme. Ens ha deixat només quatre obres per a orgue:

Sonata de Clarines, en Re M. Manuscrit AMM 85, 36-39 i una còpia d'aquest a 85, 82-83.

85 MEM (1970): 20-29. La llista va precedida d'una presentació del manuscrit 37 de l'Orfeó Català de Barcelona, actual propietari del volum autògraf de López. També cal llegir la introducció a l'edició dels "Versets per a orgue sobre el "Pange lingua" i el "Sacris solemniis", feta pel pare Gregori Estrada en el mateix volum, pp. 45-55. Els títols precedits d'un asterisc (*) es troben en l'edició d'aquest volum de MEM (1979): 161-195; la resta d'obres estan editades pel Pare David Pujol a MEM (1934).

86 No es comptabilitzen cada un dels versets, sinó que cada sèrie forma un bloc, tal com queda especificat en la llista general d'obres. 87 MARTÍN MORENO (1985): 147.

88 Obra editada a GONZÁLEZ CASADO (1991). Pedro González Casado l'atribueix clarament al nostre autor.
Juego para Clarines. $6^{\circ}$ Tono del P. Mro Fr. Benito Julià. En un quadern de "Sonatas de Organo de Joseph Regordosa". AMM 2158, 22-23.

Adagio $5^{\circ}$ Tono del P. Mro Fr. Benito Julià. AMM 2158, 24.

2 Tocatas de primer mode. Arxiu musical del monestir de Guadalupe (Cáceres). AMG.M Legajo 149, nº 19, ms.1 para órgano, f. 1-2.

Després ja ve el pare Anselm Viola i Valentí (*1738; $\dagger 1798$ ), que va ser mestre dels escolans durant uns trenta anys, amb dues interrupcions per causa de la seva salut, no massa bona. Gran pedagog musical, ha deixat escrites algunes obres vocals de gran envergadura com la missa Alma Redemptoris mater. És l'únic mestre de Montserrat de qui s'ha conservat una obra instrumental: el concert de baixó i orquestra ${ }^{89}$, així com 18 estudis per a baixó. També s'han conservat no poques obres per a orgue i/o teclat, estudiades, transcrites i editades per M. Lluïsa Cortada [CORTADA (1998)]. Aquesta autora comptabilitza 17 Sonates, algunes amb l'indicació "por Clarines"; 1 Fuga de primer to; 1 Rondó; 7 Partits, un dels quals és per a "dos Tiples"; i algunes col-leccions de $\operatorname{Versos}^{90}$.

Després d'ell ja ve el pare Narcís Casanoves i Bertran (*1747; †1799), famós com a organista i que ens ha deixat un nombre considerable d'obres escrites per a teclat i/o orgue [CODINA (1993)]. Moltes de les seves obres van ser objecte d'estudi dels escolans i altra gent, ja que es troben copiades en diferents quaderns d'estudi. Tota aquesta obra està editada a la col-lecció Mestres de l'Escolania de Montserrat, una part a càrrec del pare David Pujol en el vol. IV [MEM (1934)] de la col·lecció, i la resta, la gran majoria, per Daniel Codina en el vol. XV [MEM (1992)] ${ }^{91}$. A més de les grans formes musicals com les sonates, els partits o els passos, Casanoves fa servir el que en podríem dir "subformes", que és difícil poder explicar tècnicament, com són els fugace, els correado o correjat (amb un intent de catalanitzar-lo). També té una sèrie de versos per a les completes i uns altres per a la Tèrcia ${ }^{92}$.

A continuació hi ha l'obra per a teclat del pare Felip Rodríguez $(* 1760 ; \uparrow 1814)$, nascut a Madrid i escolà de Montserrat. Entrat al monestir, va fer vida monàstica a Madrid. Allí va compondre una sèrie d'obres per a teclat (Sonates amb diferents temps, minuets, rondós...) que va enviar a Montserrat i que trobem repartides i repetides en diferents quaderns d'estudi d'orgue. El pare David Pujol és qui en va fer la recerca en els manuscrits, perquè molt sovint no porten nom d'autor i en va fer l'edició crítica de bona part de les sonates ${ }^{93}$. Encara queda per fer la ressenya acurada i definitiva de les seves obres.

89 Editat pel P. David Pujol a MEM (1936) [2a ed., 1990]: 3-67. 90 CORTADA (1998): 213-216.

91 Daniel Codina ha publicat diferents treballs biogràfics del personatge. Tots es poden resumir en el més complet i recent: CODINA (2000), en l'escaiença del 200è aniversari de la mort del P. Casanoves. 92 MEM (1992): XIV-XVI. (1928). 
Josep Vinyals i Galí $(* 1771 ; \nmid 1825)$. A l'escolania va ser deixeble del pare Anselm Viola i del pare Narcís Casanoves. En un període indeterminat, possiblement no massa llarg, després de la mort del pare Casanoves el 1799, va assumir el càrrec de mestre d'escolans i va començar la seva etapa de compositor, sobretot de música vocal amb instruments, totalment inèdita. Ben aviat es trasllada a Sant Benet de Bages on fa d'organista i de compositor ${ }^{94}$. Després de la destrucció de Montserrat pels francesos va ajudar el pare Brell i el pare Boada en la recuperació escrita de l'antic arxiu musical perdut. Només se li coneix, amb seguretat, una sonata en dos moviments per a teclat ${ }^{95}$. També té tres quintets per a instruments de vent per a les processons [Editats a CODINA \& DOLCET (1996)]. Morí a Terrassa, la seva ciutat, el dia 10 de gener del 1825 .

\section{ELS QUADERNS D'ESTUDI D'ORGUE DE L'ARXIU DE MONTSERRAT}

A la represa de la institució musical de l'escolania, set anys després de l'incendi de l'església i la pèrdua dels arxius montserratins, per part dels francesos l'any 1811, el pare Jacint Boada i Casanoves, ajudat diligentment pel pare Benet Brell i Clos, i pel pare Josep Vinyals, havien d'escriure la música d'estudi per als nois que reprenien el fil trencat. Ho havien perdut quasi tot i van haver d'escriure la música d'estudi que necessitaven sobretot de cara al culte litúrgic i religiós. A més, havia de ser una música adaptada als nois que començaven l'estudi de l'orgue.

Tenim la sort d'haver pogut trobar, entre els molts quaderns existents, el primer que el pare Jacint Boada va escriure en la represa de l'escolania l'any 1818, any en el qual es va tornar a obrir l'escolania després de set anys de pausa ${ }^{96}$. Els nois, vuit en total, van entrar el mes de març i aquest quadern d'orgue està datat el 15 de juliol i destinat a Pau Cortada d'Olesa de Montserrat ${ }^{97}$, un dels vuit. A aquest quadern en van seguir molts d'altres fins a la desfeta de la desamortització el 1835. Sovint són còpia del pare Jacint Boada, i, encara que estiguessin destinats a un escolà concret, van servir també per a d'altres estudiants ${ }^{98}$. Cal remarcar que quan el monestir estava clausurat per la desamortització, el pare Boada va donar classes d'orgue a diferents persones, segons queda registrat, - segurament per

94 Té una missa a Sant Josep, amb orquestra, datada a Bages el 1807 (Ms. AMM124).

95 Editada a MEM (1936): 237-249.

96 Vegeu SALDONI (1856): 51. El va ajudar molt en aquesta tasca el P. Benet Brell.

97 En dóna una petita nota biogràfica SALDONI (1856): 65 .

$98 \mathrm{Cal}$ recordar que, amb una intenció pedagògica per als estudiants d'orgue, es va publicar l'edició de les sonates del P. Boada i del P. Brell d'un d'aquests quaderns primers, de l'any 1819: Benet Brell (2007) [2a ed.] i Jacint Boada (1989). Amb aquesta mateixa finalitat es va publicar: CODINA \& MOSCA (1997). A aquests quaderns cal afegirhi: MORENO (1998).
Antoni Oller - ${ }^{99}$, en el llibre d'entrades a l'escolania ${ }^{100}$. Aquestes persones van ser, segons diu la nota,

"Desde el año 1840 han aprendido y perfeccionado la Musica en este Monassterio: Juan Ricard de Monistrol, Org[anis]ta del mismo, Antonio Vidal de la Viña Bieja (sic), Esparraguera, Jayme Puig y Torrents de la Geltrú, Organista de la misma ${ }^{101}$. Magin Lluvés y Lluch, de Agramunt. Jose Rosich de Ygualada. Joaquin Oller de Bar[celo]na Org[anis] ta de Sitges".

D'altres quaderns són copiats pels mateixos escolans, $\mathrm{i}$ de vegades inclouen obres, sonates o Passos, de Casanoves, Viola o Soler ${ }^{102}$. Aquests quaderns, sobretot els primers, contenen versos per a les misses i sonates ${ }^{103}$. Cal pensar que són quaderns per a principiants; els quaderns on trobem sonates i obres del pare Casanoves o Antoni Soler són ja per a estudiants avançats o organistes ja en exercici. En tot cas hi ha poca representació d'autors forans. Sí que hi hem descobert, anònima, la famosa sonatina en Do de Clementi ${ }^{104}$ : obra que encara serveix molt actualment per a l'estudi dels escolans principiants del piano. Però ben d'hora, sobretot quan Rafael Palau ${ }^{105}$ és escolà (1821-1822 i 1824-1826) i quan era ja jove monjo i començava a copiar obres per a orgue (entre els anys 1826 i 1835), trobem que comencen a posar-se de moda algunes simfonies de les òperes italianes, especialment les del prolífic Gioachino Rossini (*1792; †1868), reduïdes a versió de piano o d'orgue.

El fet de l'exclaustració a causa de la desamortització (1835-1845) va suposar una ruptura important pel fet de tenir clausurada l'escolania i l'ensenyament musical a Montserrat ${ }^{106}$.

99 Antoni Oller, antic deixeble del pare Boada a l'escolania (1818-1822), fou el primer mestre d'aquesta quan fou restaurada l'any 1854; en aquell moment, Oller, que havia estat mestre de la capella reial de Madrid, estava ja jubilat; va estar al davant de l'escolania els anys 1854 fins el 1857.

100 Arxiu de Montserrat AI a 15, sense paginació: Llibre registre d'entrades a l'escolania, 1818-1925. durant l'exclaustració (18351844), Montserrat. Butlletí del Santuari, $\mathrm{n}^{\circ} 23$ (1989), p. 39, nota 9).

101 SALDONI (1868-1881): IV, 165.

102 Vegeu Introducció a MEM (1992): VIII-XIV, on faig la ressenya de les fonts manuscrites de les sonates del P. Narcís Casanoves en diferents arxius, sobretot el de Montserrat; aquests quaderns gairebé sempre foren copiats per escolans o antics escolans que els tenien a casa per estudiar.

103 És la pràctica que se seguia al monestir segons la normativa de les Constituciones de Valladolid des del moment de la reforma el 1493.

104 Muzio Clementi $(* 1752 ; \dagger 1832 .$. Es troba en el ms. AMM 2386, 6-7, amb el títol: "Sonata facil", en un quadern copiat entre 18201824.

105 (*Granollers, 1810; †La Garriga, 1890). Va ser mestre de l'escolania durant uns mesos l'any 1835; en ser exclaustrat va anar a França ocupant el càrrec d'organista de Montpeller. El 1853, al moment de la restauració de l'escolania va tornar a ser-ne mestre, però poc temps, per tal de retirar-se a La Garriga. Va deixar tot el seu arxiu musical a Montserrat.

106 Vegeu, però, nota 99. 
I ací podem posar fi a aquest estudi, tot i que en la represa l'any 1851 de la mà de l'incombustible pare Boada, va passar de seguida l'ensenyament musical a Rafael Palau (que va durar poc temps), i a dos antics deixebles seus, Antoni Oller (1854-1857) ${ }^{107}$ i Bartomeu Blanch (1857-1865) ${ }^{108}$. Aquests continuaren, pràcticament, la mateixa manera antiga d'ensenyar; Blanch, però, va ser un mestre prolífic en la composició d'exercicis musicals i obres d'estudi.

\section{CONCLUSIÓ}

Aquest estudi ha volgut resseguir, en primer lloc, les persones que a Montserrat mateix han estudiat, exercit el càrrec d'organista i deixat material d'estudi i segonament, l'obra pedagògica escrita i el material o quaderns d'estudi que l'escola de Montserrat ha generat i ens ha pervingut fins avui, sobretot, en el període de represa després de la destrucció dels arxius musicals. El valor que hagi pogut tenir aquesta escola s'ha de mesurar pel resultat de la formació dels organistes que ha tingut, que de segur no és menyspreable, però també per la continuïtat a través dels temps i de les noves formes musicals. A més cal no perdre de vista que estava subjecta a la funció litúrgica i religiosa del santuari, tot $\mathrm{i}$ que, per la pèrdua de la documentació històrica $\mathrm{i}$ en part de la musical, no sabem gairebé res del que passava en èpoques passades, que segurament ens donarien força sorpreses. Només cal afegir que el repertori que ens ha quedat escrit és prou gran $\mathrm{i}$ interessant $\mathrm{i}$, si ha arribat a nosaltres, és perquè van ser escrites per a ser estudiades, ja que els grans organistes com Narcís Casanoves, Anselm Viola o Benet Brell, eren grans improvisadors $\mathrm{i}$ això vol dir que la major part de la musica que van produir no ha quedat escrita.

\section{BIBLIOGRAFÍA}

Actes del I Symposium de Musicología Catalana: Joan Cererols i el seu temps, Barcelona, Institut d'Estudis Catalans, 1985.

Altés i Aguiló, Francesc Xavier, “A través dels orgues de l'església-basílica de Montserrat”, (Piqué i Collado, JordiAgustí, ed.) La llum del so. El nou orgue de Montserrat. Montserrat, Publicacions de l'Abadia de Montserrat, 2011, 19-47.

Anglés Pámies, Higinio, "Síntesis biográfica de Cabanilles", Anuario Musical, 17 (1962).

Benet Brell (1786-1850), 6 sonates per a piano, primer curs. Montserrat, Publicacions de l'Abadia de Montserrat, 2007.

107 Vegeu notes 102 i 103.

108 Bartomeu Blanch nasqué a Monistrol de Montserrat l'any 1816 i morí a Buenos Aires (Argentina) l'any 1891. En sortir de l'escolania el 1832, obtingué el càrrec d'organista de Cardona; després fou mestre de música de Berga i finalment organista i mestre de capella a Terrassa, fins que entrà de mestre a Montserrat.
Benet Julià. Obres completes, I, Montserrat, Abadia de Montserrat, col. "Mestres de 1'Escolania de Montserrat, XIII", 1989. [= MEM (1989]

Benet Julià. Obres completes, II, Montserrat, Abadia de Montserrat, col. "Mestres de l'Escolania de Montserrat, XIV", 1991. [= MEM (1991]

Capdepón Verdú, Paulino, El padre Antonio Soler (1729-1783). Biografia y obra musical. Olot, Arxiu Històric Comarcal d'Olot, Museu Comarcal de la Garrotxa, sèrie "Beques Ciutat d'Olot", 2000.

Catalogo de los Monges que siendo Niños, sirvieron de Escolanes y Pages á la Reyna del Cielo la Virgen de Monserrate en esta su Santa Casa, Arxiu de Montserrat, manuscrit $\mathrm{n}^{\mathrm{o}} 28$.

Ceremonial Monástico conforme al Brebiario, y Missal, que la Santidad de Paulo V, concedió a todos los que militan debaxo de la santa Regla de nuestro gloriosisimo padre, y Patriarca de las Religiones S. Benito: con los usos y costumbres loables de la Congregación de España, Salamanca, Jacinto Tabernier, 1635.

Codina i Giol, Daniel, “Aproximació a l'obra per a tecla del P. Narcís Casanoves (1747-1799)", Anuario Musical, 48 (1993), 143-151.

Codina i Giol, Daniel, "La capilla de música de Montserrat a finales del siglo XVII. Datos para su historia”, a Monjes y monasterios españoles, Actas del Simposium de San Lorenzo del Escorial (1995), 787-809.

Codina i Giol, Daniel \& Dolcet Rodríguez, Josep, Sis Quintets per a Instruments de Vent (1804). Barcelona, Tritó, 1996.

Codina i Giol, Daniel, "El P. Maur Ametller i Paguina, monjo, músic i inventor (II): el Velacordi”, Montserrat. Butlletí del Santuari, 56 (2000a), 39-47.

Codina i Giol, Daniel, "El Pare Narcís Casanoves i Bertran (1747-1799), sabadellenc, monjo de Montserrat i músic eminent", Arraona, 23 [Sabadell] (2000b), pp. 27-44.

Codina i Giol, Daniel, "Gènesi i publicació del volum de les misses tonals del pare Joan Cererols (1618-1680)", Revista Catalana de Musicología, VI (2013), 31-46.

Codina i Giol, Daniel; \& Mosca, Ludovico, Narcís Casanoves $i$ Bertran (1747-1799), 6 Sonates per a piano. Montserrat, Publicacions de l'Abadia de Montserrat, 1997.

Codina i Giol, Daniel; \& Sans i Fàbregas, Llorenç, "Jaume Vidal, la recuperació d'un santfeliuenc (1607-1689)", Quaderns d' Història, 4 [Sant Feliu de Llobregat, Ajuntament, patronat Municipal de Cultura] (1989), 52pp.

Cortada i Noguero, Maria Lluïsa, Anselm Viola. Compositor, pedagog, monjo de Montserrat (1738-1798), Montserrat, Publicacions de l'Abadia de Montserrat, 1998.

González Casado, Pedro, Obras para Fortepiano. Codina, Jacinto; Martí, José; Murguía, Joaquín Tadeo; Teixidor, José. Madrid, Real Conservatorio Superior de Música de Madrid, 1991.

Jacint Boada (1772-1859) - Benet Brell (1786-1850). 8 sonates per a piano, segon curs. Montserrat, Publicacions de l'Abadia de Montserrat, 1989. 
Jambou, Louis, Evolución del órgano español. Siglos XVIXVIII, Oviedo, Universidad de Oviedo, 1988.

Jambou, Louis, "Tiento", Diccionario de la Música Española e Hispanoamericana. Vol. 10. Madrid, SGAE, 2002, 292296.

Jeffery, Brian, Ferran Sors, compositor i guitarrista. Montserrat, Publicacions de l'Abadia de Montserrat, col. "Textos i Estudis de Cultura Catalana", 1977.

Kenyon de Pascual, Beryl, "Los seis conciertos par dos órganos obligados del padre Soler y el instrumento para el que probablemente fueron escritos", Revista de Musicología, VIII/1 (1985), 41-45.

Llorens Cisteró, José M " "Repercusión de las obras de José Elías en la formación musical organística del padre Antonio Soler (1729-1783)", Revista de Musicología, VIII (1985), 23-28.

Martí i Marvà, Jaume, Memorial ó Tratado a favor de los Niños escolanes y Seminario de Nuestra Señora de Monserrate, Tolosa, Juan Boude, 1650 (reimpr. Manresa, Pau Roca, s.d.).

Martín Moreno, Antonio, Historia de la Música Española. Siglo XVIII. Madrid, Alianza, 1985.

Miquel López. Obres completes, I, Montserrat, Abadia de Montserrat, col. "Mestres de 1'Escolania de Montserrat, VI", 1970. [= MEM (1970)]

Moreno i Morera, Modest, P. Benet Brell (1786-1850) monjo de Montserrat, Tema amb variacions. Ripoll, Centre d'Estudis Comarcals del Ripollès, 1998.

Música Instrumental, I. Obres musicals dels monjos del Monestir de Montserrat 1500-1800. Miquel López, Montserrat, Abadia de Montserrat, col. "Mestres de 1'Escolania de Montserrat, I", 1934. [= MEM (1934)]

Música Instrumental, III. Narcís Casanoves i Bertran, Montserrat, Abadia de Montserrat, col. "Mestres de l'Escolania de Montserrat, XV”, 1992. [= MEM (1992)]

Nassarre, fray Pablo, Escuela Música según la práctica moderna. 2 vols. Zaragoza, Herederos de Diego de Larumbe, 1724 y 1723.
Nin, Joaquín, Classiques espagnols du piano. París, Eschig, 1928.

Noviala, Manuel, Breve Tratado del Seminario de los Niños Escolanes o, Ynfanticos, del Real Monasterio de $N^{a} S^{a}$ de Monserrate, Biblioteca de Montserrat, manuscrit $n^{\circ} 964$.

Oranias i Orga, Ramon, "Els orgues grans de Montserrat", en curs de publicació.

Pujol, David, Música Instrumental, II. Anselm Viola, Felip Rodríguez i Josep Vinyals. Montserrat, Abadia de Montserrat, col. "Mestres de 1'Escolania de Montserrat, V", 1936. [= MEM (1936)]

Querol Gavaldá, Miguel, "Montserrat", (Blume, Friedrich, ed.) Die Musik in Geschichte und Gegenwart. Allgemeine Enzyklopädie der Musik. Vol. 9. Kassel, Bärenreiter, 1961, cols. 536-541.

Ràfols i Fernández, Antoni, Tratado de la Sinfonia, Reus, Rafael Compte-Francisco de Paula Compte, 1801.

Rubio Calzón, Samuel, Antonio Soler. Catálogo crítico. Cuenca, Instituto de Música Religiosa de la Diputación Provincial de Cuenca, 1980.

Saldoni y Remendo, Baltasar, Reseña historica de la Escolanía ó Colegio de Música de de la Vírgen de Montserrát en Cataluña, desde 1456 hasta hoy dia, con un catálogo de algunos de los maestros que ha habido, Madrid, Impenta de Repullés, 1856.

Saldoni y Remendo, Baltasar, Diccionario Biográfico-Bibliográfico de Efemérides de Músicos españoles, 4 vols., Madrid, Antonio Pérez Dubrull, 1868-1881.

Segarra i Malla, Ireneu: "Introducció", Miquel López. Obres completes, I, Montserrat, Abadia de Montserrat, col. "Mestres de 1'Escolania de Montserrat, VI", 1970, pp. 13-14.

Sor, Ferran: "Sor", Encyclopédie Pittoresque de la Musique. París, H. Delloye, 1835.

Recibido: 30.01 .2018

Aceptado: 16.04.2018 